OPEN ACCESS

Edited by:

Armin Pircher Verdorfer,

Technische Universität München,

Germany

Reviewed by:

Arianna Costantini,

Università degli Studi di Verona, Italy

Latha Poonamallee,

The New School, United States

${ }^{*}$ Correspondence:

Matej Černe

matej.cerne@ef.uni-lj.si

Specialty section:

This article was submitted to

Organizational Psychology,

a section of the journal

Frontiers in Psychology

Received: 31 May 2018

Accepted: 19 November 2018

Published: 04 December 2018

Citation:

Bunjak A and Černe M (2018)

Mindfulness - The Missing Link

in the Relationship Between Leader-Follower Strategic Optimism (Mis)match and Work Engagement.

Front. Psychol. 9:2444

doi: 10.3389/fpsyg.2018.02444

\section{Mindfulness - The Missing Link in the Relationship Between Leader-Follower Strategic Optimism (Mis)match and Work Engagement}

\author{
Aldijana Bunjak ${ }^{1}$ and Matej Černe ${ }^{2 *}$ \\ ${ }^{1}$ School of Management, University of St. Gallen, St. Gallen, Switzerland, ${ }^{2}$ Faculty of Economics, University of Ljubliana, \\ Ljubljana, Slovenia
}

Assuming a followership perspective and building on implicit leadership theory, this study examines the mediating role of followers' mindfulness in the relationship between leaderfollower strategic optimism (mis)match and work engagement. Specifically, we propose that a discrepancy between the respective levels of leaders' and followers' strategic optimism correlates with low levels of mindfulness and work engagement. A field study of 291 working professionals, using polynomial regression and response surface analysis, supports the (mis)match hypotheses. The results demonstrate that followers' mindfulness mediates the relationship between leaders' and followers' matching levels of strategic optimism (whether at high-high and low-low leader-follower strategic optimism conditions) and work engagement. These findings have important implications for training and the extent to which interventions based on personal resources, such as strategic optimism and therefore mindfulness, foster higher work engagement.

Keywords: strategic optimism, leader-follower (mis)match, implicit leadership theory, followership, mindfulness, work engagement

\section{INTRODUCTION}

Although leaders' personal characteristics determine a broad range of followers' performance outcomes (Ilies et al., 2005; Tims et al., 2011; Dinh and Lord, 2012), comparatively little is known about followership (Bligh, 2011; Uhl-Bien et al., 2014; Leroy et al., 2015) and how followers conceive their cognitive attributes relative to leaders' characteristics. Followers are matched with a leader possessing either similar or strikingly different cognitive characteristics, and such a dyadic situation at work influences the joint relationship dynamics, thereby impacting followers' work outcomes, i.e., work engagement (Shamir, 2007; Schyns and Sanders, 2007; Gooty et al., 2009; Felfe and Schyns, 2010).

In the last few years, positive organizational scholarship (e.g., Cameron and McNaughtan, 2014) and positive organizational behavior (e.g., Luthans and Avolio, 2009) have gained momentum in research. Their representing constructs, such as optimism (Youssef and Luthans, 2007; Avey et al., 2011), are receiving increasing attention and have been shown to be associated with desired workrelated employee outcomes (Luthans et al., 2007; Avey et al., 2009). Specifically, strategic optimism refers to a cognitive strategy used by individuals that is characterized by the following: they enjoy a sense of control over a given situation; they can perform with minimal anxiety; and they set high expectations, on the basis of past success, thereby avoiding reflection on potentially negative 
outcomes (Chang et al., 2009). The question then arises whether strategically optimistic followers feel better about their leaders when they perceive them as like-minded relative to themselves. Even more important is the effect on followers' work engagement in the opposite condition; that is, when followers' perception of leaders' strategic optimism does not match.

Building on previous research on implicit leadership theory (ILT; Shondrick et al., 2010; Epitropaki et al., 2013), followers compare the characteristics of their actual leader to their "ideal" conception of a leader, and any discrepancy between the two modifies (positively or negatively) the followers' impressions of their leader (Lord and Hall, 2003; Lord and Brown, 2004). This perceived similarity is a crucial factor in establishing positive leader-follower relationships (Cornelis et al., 2006; Brouer et al., 2009), in particular because followers' subjectively perceived similarity (i.e., individuals' beliefs about how similar they are to a leader) is even more important than actual resemblance (Watson et al., 2000; Montoya et al., 2008; Fischer, 2009).

Following the preceding logic, we argue that followers with high or low strategic optimism are prone to be affected by their leaders' strategic optimism. Although self-evaluation (i.e., followers' intrapersonal evaluation) is considered to be an implicit process (Pelham et al., 2002), evaluation of others (i.e., interpersonal evaluation) triggered by welcoming information of perceived similarity is instead a controlled process which involves conscious effort and awareness (Von Hippel and Trivers, 2011). Specifically, we argue that the perceived similarity in cognitive strategies (Harrison et al., 2002) triggers corresponding psychological processes, such as enhanced attention and awareness, which is further regarded as the fundamental component of mindfulness (Teasdale et al., 2002; Brown and Ryan, 2003; Kabat-Zinn, 2003; Baer et al., 2006; Grabovac et al., 2011; Mikulas, 2011). Positive association with self (Pelham et al., 2005) may stimulate followers to pay more profound attention, including higher levels of awareness of personal attraction to a leader (Kristof-Brown et al., 2005; Edwards and Cable, 2009). Such interplay is particularly relevant to work-related outcomes, such as work engagement (Leroy et al., 2013; Malinowski and Lim, 2015). This is so because followers who identify more closely with a leader are more responsive and willing to subordinate themselves to that leader (Lord and Maher, 1991; Eagly and Karau, 2002; Lord and Hall, 2003; Brouer et al., 2009).

The intended contributions of this study are three-fold. First, by investigating the proposed expectation-perception model with the focus on followers' subjectively perceived similarity with the leader (Toma et al., 2012), we contribute to the literature related to ILT and followership by explaining when and why a (mis)match between followers' and leaders' strategic optimism is likely to occur (Schyns and Meindl, 2005; Schyns and Day, 2010), and how this mechanism supports followers' awareness of similarities by fostering the joint relationship and, in turn, followers' work engagement. Second, our study contributes to the research on cognitive strategies (i.e., strategic optimism) by proposing that the positive effect of a follower's strategic optimism depends on a leader sharing a similar level of strategic optimism, thereby contributing to the follower's awareness of the suitability of the leader-follower relationship and heightened awareness. Third, we contribute to the mindfulness literature by providing insights into the conditions under which mindfulness may emerge, flourish and lead to beneficial outcomes. Specifically, assuming the follower's perspective, positive association between oneself and the leader spurs emergence of awareness (i.e., heightened mindfulness). Therefore, the main message of this study is that a leader-follower strategic optimism match, through mindfulness, should foster superior levels of employee work engagement.

\section{THEORY AND HYPOTHESES}

Studies have criticized traditional leadership theories for placing undue emphasis on the impact of leaders' characteristics on followers' attitudes and behaviors (Graen and Uhl-Bien, 1995; Uhl-Bien et al., 2014). As a response, followership literature is concerned with articulating effective follower characteristics, follower behaviors, and outcomes relative to leaders (Meuser et al., 2016). Followership theory argues that leadership cannot be fully understood without a meaningful consideration of the followers' impact on the leadership process (Dvir and Shamir, 2003; Sy, 2010).

Even though leaders and followers influence each other's perceptions (Pirola-Merlo et al., 2002), research has shown that followers' self-evaluation significantly influences their assessment of the leader (Hall and Lord, 1995; Howell and Shamir, 2005). The way that one views oneself (i.e., the psychological process of positive association with self) significantly determines the way one perceives others, i.e., how a follower sees a leader (Keller, 2003). Naturally, leaders are not all perceived as leaders, and this leadership perception depends enormously on the leader's actual characteristics, behavior, and skills (Cavazotte et al., 2012) and on followers' conceptions of an ideal leader (Epitropaki and Martin, 2004). A leader is a product of the overlap between followers' identification with their ideal conception of a leader and the leader's actual characteristics (Lord et al., 1984). This ideal image of a leader is formed through previous interactions with different leaders (Ritter and Lord, 2007) and role models, such as parents (Keller, 2003).

Dinh and Lord (2012) observed that followers use implicit leadership principles to arrive at conclusions about others' leadership based on their personal characteristics. In other words, followers' perceptions of leaders' characteristics are crucial to their categorization of a leader (Shondrick et al., 2010). Implicit leadership is a process whereby perceivers, based on cognitive structures, subjectively observe the world, including the characteristics of others, around them (Epitropaki et al., 2013). The process enables the observation of a leader's actual characteristics, as well as their "ideal" characteristics, to make sense of the leader's behavior (Medvedeff et al., 2007). A match between leaders' characteristics and the characteristics of followers' leader prototypes (Lord et al., 2001) will prompt followers to accept the leader as someone truly capable of leading them and their team. The match will promote followers' positive behavior and foster good attitudes toward their 
leader. By contrast, a mismatch will result in negative workrelated outcomes, such as high turnover and followers' general dissatisfaction (Engle and Lord, 1997).

Furthermore, research shows that individuals prefer to socialize with individuals who share common behavior, preferences, and personality dimensions, such as strategic optimism (Reis et al., 2000; Shondrick et al., 2010). Additionally, van Quaquebeke et al. (2011) found that when followers are asked to evaluate their leaders, the evaluation is not only influenced by self-perception, but also by the extent to which followers perceive themselves as similar to their leaders. Thus, followers who regard their relationship with a leader as poor and have (mis)matched expectations may experience reduced commitment to the leader and the organization, thereby resulting in negative work outcomes, i.e., decreased levels of work engagement (Van Breukelen et al., 2002).

\section{The Congruent Effect of Leader-Follower Strategic Optimism on Followers' Mindfulness and Work Engagement}

Unlike the trait-like form of optimism, which is relatively stable and rigid (Scheier and Carver, 1987), state-like strategic optimism is a cognitive strategy associated with a specific problem or goal within a particular situation and temporal context (Norem, 2001). Research has proven strategic optimism to be a powerful motivator, suggesting that this cognitive strategy enables individuals to set high expectations, and avoid reflecting unnecessarily on upcoming events (Norem and Illingworth, 1993). This coping mechanism is even more relevant nowadays, when leaders and followers have virtually no choice but to operate under great stress and anxiety in different work situations (Blaskovics, 2014). Similarly, a leader-follower match in strategic optimism is equally important, because a match in leaderfollower cognitive strategy seems to represent a precondition for a healthy relationship between the two component parties in this association (Bunjak and Černe, 2018).

If we peer through the lens of ILT, expectations set by a strategic optimist (Spencer and Norem, 1996) will greatly depend on expectations of a leader (Biddle, 1979). Consequently, when leaders and followers share common expectations that are shaped by cognitive characteristics, such as strategic optimism, followers will find their jobs more pleasurable than they will in a mismatch situation. Leaders who score low in strategic optimism with followers who maintain high strategic optimism will be regarded as unpleasant, overly nervous, negative, and controlling (Rowold and Schlotz, 2009). Similarly, a leader who scores high in strategic optimism might be regarded as insufficiently consistent in and serious about their work (Taylor and Brown, 1988).

In the same vein, leader-member exchange (LMX) research builds on implicit theory, noting that individuals will thrive most at work when they perceive the leading party to contribute equally or more to the relationship (Buunk et al., 1993). Accordingly, with more consistency, and thus more similarity between the leader prototype (i.e., followers' implicit expectations) and the actual leader's characteristics (Scott and Brown, 2006), the more the leader is regarded as contributing to the LMX relationship (van Gils et al., 2010). Moreover, followers will more easily relate to and understand information about the leader when the specific leader's characteristics are similar to (i.e., matched with) the followers' implicit leadership expectations (Shondrick et al., 2010). For example, if followers perceive themselves as being strategic optimists, they will expect their leader to act similarly (Montoya and Horton, 2013), to provide a corresponding contribution to the joint relationship, thereby maximizing the work outcome (i.e., follower' work engagement).

Similarly, ILT enables individuals to make sense of leaders' characteristics (Shondrick et al., 2010) based on self-perception relative to others (Junker and van Dick, 2014) and previous social experiences (Keller, 1999). Hence, based on ILT, a match of leader-follower strategic optimism implies high levels of self-perception and self-perception relative to others, that is, perspective-taking (Galinsky and Moskowitz, 2000; Parker and Axtell, 2001). More specifically, perspective-taking refers to an individual's ability to see the world as others see the individual (Edwards et al., 2017).

We therefore believe that an ILT explained in terms of coordination between "I" and "You" [i.e., as with a (mis)match between leader and follower strategic optimism] also involves features of mindfulness, that is, enhanced attention to and awareness of self (i.e., follower) relative to other (i.e., leader). Moreover, in our study, mindfulness regarded as a state [rather than as a trait, agreeing with a recent meta-analysis that identified the malleability of this construct (Eberth and Sedlmeier, 2012)], emerges only when attention to present circumstances (in this sense, attention of leaders' characteristics) is intentionally evoked (Chiesa, 2013). In this state of mind, an individual takes no action, but simply acknowledges and observes the changing flow of thoughts as they arise moment by moment (KabatZinn, 2003). Specifically, the very moment of followers' perceived similarity with the leader [in our study, this was intentionally evoked by asking participants to evaluate their leaders' deep level psychological characteristics (Harrison et al., 2002)] such as strategic optimism, triggers attention to and awareness of present reality [i.e., (mis)matched leader-follower cognitive characteristics], and thus mindfulness (Brown and Ryan, 2003). This leads to our hypotheses, formulated as follows:

Hypothesis 1a: When leader and follower match in strategic optimism at low levels, the level of follower's mindfulness is high.

Hypothesis 1b: When leader and follower match in strategic optimism at high levels, the level of follower's mindfulness is high.

Studies have shown that leadership is in the eye of beholder (Gooty et al., 2009). The greater the consistency of the components of follower perception, the more efficiently leaders are at directing follower attitude and work-related outcomes (Fleenor et al., 2010). Matching at deep-level similarities, such as leader-follower strategic optimism (Oakes et al., 1991), invokes mindful information processing, which lends clarity to the interpretation of explicit leader behavior (Lord and Maher, 1991). Moreover, followers who acknowledge similarities with leaders' 
characteristics and relationship fit will experience commitment and engagement (Chalofsky and Krishna, 2009), as well as identification of the benefit of a leader as their own (Sluss and Ashforth, 2007). In addition, follower mismatch with a leader's characteristics (see Figure 1: either follower strategic optimism $>$ leader strategic optimism or follower strategic optimism $<$ leader strategic optimism) will result in follower turnover, absenteeism, lack of commitment, and poor engagement (Jones and Harter, 2005; Albrecht and Andreetta, 2011).

Particularly, matched expectations (i.e., similarity with the leader) evoke awareness of such inner experience, making people receptive and attentive to present occurrences (Brown and Ryan, 2003). After all, followers' will prioritize and be open-minded about welcome (i.e., matched strategic optimism) more than unwelcome (i.e., mismatched strategic optimism) information about their leaders (Von Hippel and Trivers, 2011). On the other hand, mindfulness channels awareness of thoughts, sensations, and individuals' attention to the present experience (Bishop et al., 2004; Feldman et al., 2010) in an open manner, which may improve cognitive barriers of ILT, such as inconstant information (Lord and Maher, 1991), and help individuals to keep processing actual information about leaders' characteristics and behavior at all times (Carlson, 2013; Pircher Verdorfer, 2016). Moreover, mindfulness facilitates prioritizing, limiting, and directing information (Jha et al., 2007); reduces mind wandering (Mrazek et al., 2013); and enhances cognitive memory and operationalization of information (Zeidan et al., 2010).

Finally, when a follower's self-perception of strategic optimism, relative to a leader's strategic optimism is strongly aligned, the individual perceives the leader as a part of their self-concept (Lord and Brown, 2001). Such individuals tend to contribute beneficially to their leaders and organization (KristofBrown et al., 2005), thereby increasing work engagement (Gardner et al., 2005). Likewise, engaged employees tend to be regarded as immersed, fully present, and attentive in their activities (Rich et al., 2010), and mindfulness further enhances those positive experiences, by making them clear and vivid as they occur (Brown and Ryan, 2003). In other words, alert attentiveness that describes evaluation of the leader can be fully attendant to by a followers' mind that is aware of what takes place in the present moment (Good et al., 2016). Therefore, we propose:

H2: Mindfulness mediates the relationship between leaderfollower strategic optimism match and work engagement.

Figure 2 presents our conceptual model with hypotheses.

\section{MATERIALS AND METHODS}

\section{Data Collection Procedure}

An online questionnaire of working professionals was conducted in spring 2016. Participants were recruited via posts on social networking websites, such as Facebook and LinkedIn. Potential participants were also targeted through various groups (e.g., Happiness at Work, Business Psychology at Work, Employee Engagement, and Cognitive Neuroscience) and via personal contacts. The participants were notified that the aim of the research was to explore the dynamics perceived by employees at their workplace. After agreeing to participate, participants were directed to the survey website. The survey took approximately 10 min to complete.

\section{Sample}

The mandatory requirement for study participation, for working professionals, was that the participants be employed. In line with our follower-centric theoretical perspective, our mode of data collection relied completely on self-reporting, from

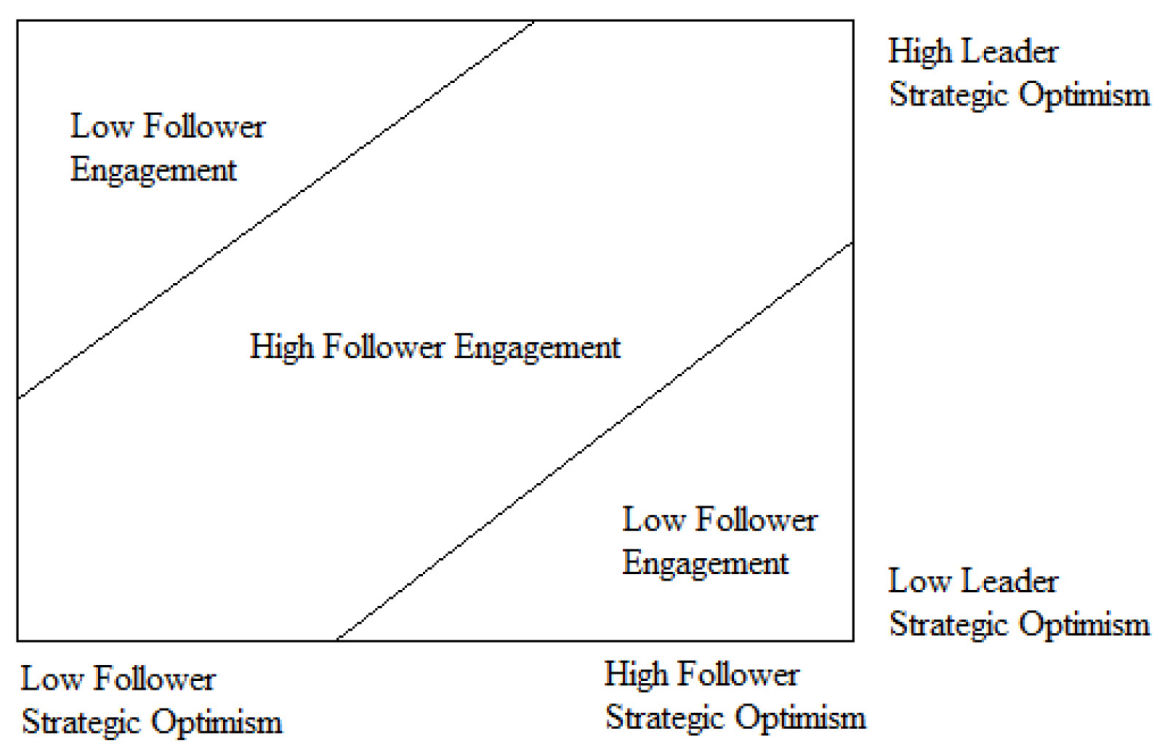

FIGURE 1 | Follower engagement (mis)match model. 


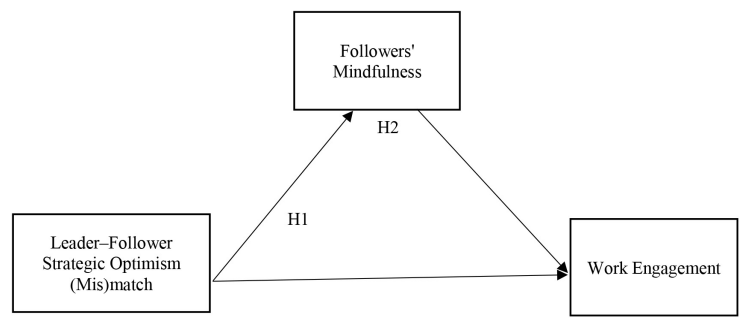

FIGURE 2 | Research model with hypotheses.

the perspective of the employees, who gave responses about themselves and their leaders. The online survey was completed by 291 employees; $65 \%$ of respondents were female, and approximately $45 \%$ were less than 35 years of age. Most of the participants had acquired a master's level degree (44.4\%), and they were from the United States (21.4\%), Slovenia (19.1\%), Bosnia and Herzegovina (10.6\%), the United Kingdom (6.4\%), and Australia (4.8\%). Their main fields of employment were education $(34 \%)$, finance $(17.2 \%)$, the service industry $(12.4 \%)$, health care (10\%), and government (9.3\%). The majority $(55.3 \%)$ had less than 3 years of work experience with their leaders, followed by $26.1 \%$ who had 3-6 years of dyadic tenure, $9.3 \%$ with $7-10$ years of dyadic tenure, and $9.3 \%$ with 11 or more years of dyadic tenure experience.

\section{Measures}

This study used five-point Likert-type scales ranging from 1 ("strongly disagree") to 5 ("strongly agree"). The measures were administered in the English language.

\section{Follower's Strategic Optimism}

The strategic optimism scale was adapted from the defensive pessimism scale (Norem, 2001), which consists of several items that refer to the process of thinking through things, as well as items designed to measure strategic optimism. For the purpose of this study, we only selected items that measure strategic optimism. A sample item was "I go into these situations expecting the worst, even though I know I will probably do OK." ( $\alpha=0.63)$.

\section{Leader's Strategic Optimism}

As in the assessment of followers' strategic optimism, the Strategic Optimism Questionnaire (Norem, 2001) was used. Because we wanted to assess how followers perceive their leaders, in the follower domain, the scale was adapted to include a referent shift to the leader. Accordingly, a sample item was " $\mathrm{He} /$ she goes into these situations expecting the worst, even though he/she knows he/she will probably do OK." ( $\alpha=0.71)$.

\section{State Mindfulness}

Mindfulness was assessed using the five items with the highest factor loadings, adapted from the Mindful Attention Awareness Scale (MAAS; Brown and Ryan, 2003). Sample items included "Today, I found it difficult to stay focused on what's happening in the present," and "Today, I found myself doing things without paying attention." Participants were asked to indicate the extent

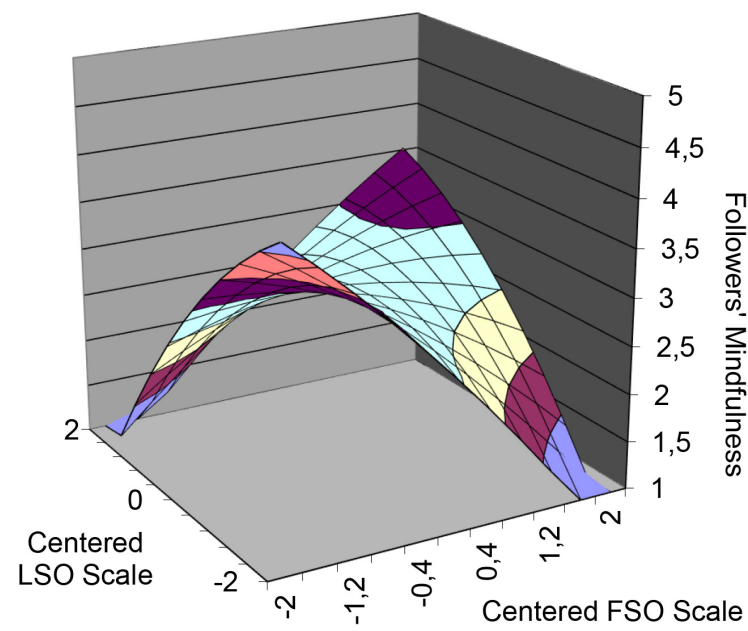

FIGURE 3 | Leader-follower strategic optimism (mis)match matrix predicting followers' mindfulness. LSO = Leader's strategic optimism; FSO = Follower's strategic optimism.

to which these items described their feelings and behavior during working hours $(\alpha=0.79)$.

\section{Work Engagement}

Work engagement was assessed using the six items with the highest factor loadings adopted from the Utrecht Work Engagement Scale (UWES; Schaufeli et al., 2002), and treated as an overall index consisting of vigor, dedication, and absorption. Example items for these components were, respectively, "At my work, I feel bursting with energy," "I am enthusiastic about my job," and "I feel happy when I am working intensely." ( $\alpha=0.89)$.

\section{Control Variables}

We controlled for four variables (i.e., age, gender, employee education, and tenure an employee has with their leader) in our analyses, because previous studies have shown these to be related to employee work engagement (Mauno et al., 2005; Avery et al., 2007). ${ }^{1}$

\section{Analyses}

In order to reduce potential common method bias effects, we conducted several a priori steps. First, our survey was part of a larger data collection, rendering respondents unlikely to guess the purpose of the study. Second, several items were reverse-coded. However, given the cross-sectional and single-source nature of our research, we also applied the marker variable test developed by Lindell and Whitney (2001) using a theoretically unrelated variable (i.e. marker variable) to adjust the correlations among the principal constructs in the model. Any high correlation of the marker variable with any other of the study's principal constructs would indicate potential common method bias. For robustness,

${ }^{1}$ Following the action editor's suggestions and referring to the work of Becker et al. (2016), we have re-done the analyses without control variables of age, gender, education, and leader-follower dyadic tenure; the results remained substantially unchanged with regards to tests of hypotheses and the strength and direction of main relationships. 
we separately repeated the marker variable test with an additional variable that was not included in the model [the Big 5 personality trait of conscientiousness, tapped by a short measure, presented by Gosling et al. (2003)], for which we had little or no theoretical basis to expect a relationship with the study's principal constructs. The average correlation between the study's principal constructs and conscientiousness $(r=0.09)$ was low and not significant, and the integration of this variable into the research model did not alter the significance of the main studied relationships, providing no evidence of common method bias.

Polynomial regression analysis and response surface modeling were applied to test the (mis)match hypotheses (Edwards and Parry, 1993). We centered the scales to reduce multicollinearity between the component measures (i.e., leader and follower strategic optimism) and their associated higher-order terms (Aiken et al., 1991). To test the mediating hypothesis, we applied the block variable approach suggested by Cable and Edwards (2004) for mediation analysis. The block variable approach involves obtaining a single coefficient that summarizes the effects of a set of conceptually related variables (Cable and Edwards, 2004). Accordingly, we constructed a block variable by first regressing the dependent variable (i.e., work engagement) on the five polynomial terms. We then used the respective weights, which were the estimated regression coefficients in the polynomial regression (i.e., $b_{1} \mathrm{X}+b_{2} \mathrm{Y}+b_{3} \mathrm{X}^{2}+b_{4} \mathrm{XY}+b_{5} \mathrm{Y}^{2}$ ), and combined the five terms into a block variable as a weighted composite (Cable and Edwards, 2004) that summarized the effects of leader-follower strategic optimism (mis)match on work engagement (Edwards and Cable, 2009). Lastly, we conducted mediation analysis using the PROCESS macro (Preacher and Hayes, 2004), with the block variable for strategic optimism as the independent variable, followers' mindfulness as the mediating variable, and work engagement as the dependent variable. We examined the direct and indirect effects using bootstrap as a bias-correction percentile method with 10,000 samples (Cable and Edwards, 2004) and conducted bias-corrected confidence intervals (Edwards, 2002). The proposed mediation will be supported if the confidence interval of the indirect effect does not include zero.

\section{RESULTS}

Table 1 presents the descriptive statistics (means, standard deviations, and correlations) of all variables used in the study. We observed the factor structure of the focal variables, using confirmatory factor analysis procedures in AMOS software version 21. The expected four-factor solution (follower's strategic optimism, leader's strategic optimism, followers' mindfulness, and work engagement) displayed a good fit with the data [chi-square $(166)=276,371, \mathrm{CFI}=0.951, \mathrm{SRMR}=0.0748$, RMSEA $=0.048]^{2}$. The standardized factor loadings ranged from 0.34 to 0.70 for follower strategic optimism items, from 0.40

\footnotetext{
${ }^{2}$ Within-construct item (for example, items corresponding to the strategic optimism scale with other items pertaining to the same scale) residuals were allowed to correlate. Without those modification indices, the results of the model fit were chi-square $(176)=361,788, \mathrm{CFI}=0.918, \mathrm{SRMR}=0.0756$, and $\mathrm{RMSEA}=0.060$.
}

to 0.81 for leader strategic optimism items, from 0.52 to 0.83 for followers' mindfulness, and from 0.58 to 0.92 for work engagement items.

\section{Hypotheses Testing}

Hypotheses 1a and $1 \mathrm{~b}$ predict that follower mindfulness will be higher when leader's and followers' strategic optimism are congruent, whether at lower or higher levels. Table 2 shows the results of the polynomial regression analysis. The curvature (Figure 3) along the line of congruence $(\mathrm{X}=\mathrm{Y})$ was positive and significant $\left(a_{2}=0.25, p<0.05\right)$, whereas the curvature along the incongruence line $(\mathrm{X}=-\mathrm{Y})$ was negative, as expected, and significant $\left(a_{4}=-0.59, p<0.01\right)$. Therefore, Hypotheses $1 \mathrm{a}$ and $1 \mathrm{~b}$ are supported.

To test Hypothesis 2, we first computed a block variable, using the estimated coefficients predicting work engagement. We then ran a mediation analysis using the PROCESS macro (Hayes, 2013), as shown in Table 3.

Examining the mediation of follower mindfulness of the relationship between leader-follower strategic optimism (mis)match and work engagement, we generated 95\% biascorrected confidence intervals (Preacher and Hayes, 2004) for the hypothesized indirect mediating effects. The direct effect of the block variable on engagement, before the inclusion of the mediator, was significant $(b=1.23, p<0.01)$. The indirect effect of the block variable of strategic optimism, on work engagement through mindfulness, was significant $(b=0.2248)$, because the confidence interval from the bootstrap analysis excluded zero [0.0457, 0.5752], supporting Hypothesis 2. Finally, the direct effect of the block variable on work engagement, after the inclusion of the mediator, was not significant $(b=0.73, p>0.05)$.

\section{DISCUSSION}

\section{Theoretical Contributions}

First, our study contributes to the ILT by explaining the role of cognitive characteristics (mis)match in shaping followers' perceptions of an implicit relationship agreement (Schyns and Meindl, 2005; Shamir, 2007). The key to how the relationship will be defined depends on followers' perceptions, and our study identified the crucial role played by a match in strategic optimism. This agrees with work by Dinh and Lord (2012), who stated that followers use ILT to reach conclusions about leadership in others, based on followers' characteristics as well. The followers' perceptions of leaders' characteristics are thus very important in the process of categorizing a leader (Shondrick et al., 2010). Specifically, our study demonstrated that working with a leader who shares a similar cognitive style, while maintaining awareness of such similarities, may contribute to higher follower work engagement. Assuming a followership perspective, i.e., focusing on followers' perceptions of themselves and of their leaders, thus represents a viable mode of applying ILT to future research.

Second, our study contributes to the research on cognitive styles by showing that the positive effect of followers' strategic optimism depends on the extent to which followers also perceive similar levels of strategic optimism in their leader. Thus, high 
TABLE 1 | Means, standard deviations, alpha reliabilities, and correlations among variables ${ }^{a, b, c}$.

\begin{tabular}{|c|c|c|c|c|c|c|c|c|c|c|}
\hline Variable & Mean & S.D. & Alpha & 1 & 2 & 3 & 4 & 5 & 6 & 7 \\
\hline (1) Age & 3.51 & 0.78 & n.a. & - & & & & & & \\
\hline (2) Education & 2.80 & 0.79 & n.a. & $0.17^{* *}$ & - & & & & & \\
\hline (3) Gender & 1.65 & 0.47 & n.a. & -0.02 & -0.04 & - & & & & \\
\hline (4) Leader-follower dyadic tenure & 1.72 & 0.97 & n.a. & $0.27^{* *}$ & 0.04 & 0.07 & - & & & \\
\hline (5) Follower's strategic optimism & 3.35 & 0.44 & 0.63 & $-0.29 * *$ & -0.03 & $0.15^{*}$ & -0.03 & - & & \\
\hline (6) Leader's strategic optimism & 3.18 & 0.43 & 0.71 & $-0.17^{* *}$ & -0.01 & $0.16^{* *}$ & -0.01 & $0.31^{* *}$ & - & \\
\hline (7) Followers' mindfulness & 3.39 & 0.82 & 0.79 & $0.21^{* *}$ & 0.05 & -0.07 & -0.01 & $-0.26^{* *}$ & $-0.13^{*}$ & - \\
\hline (8) Work engagement & 3.61 & 0.81 & 0.89 & 0.11 & $0.13^{*}$ & 0.00 & $0.15^{*}$ & -0.02 & 0.09 & $0.21^{* *}$ \\
\hline
\end{tabular}

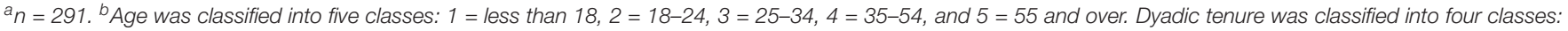
1 = less than 3 years, $2=3-6$ years, $3=7-10$ years, and $4=11$ years and over. ${ }^{c} 1=$ male, $2=$ female ${ }^{* *} p<0.01,{ }^{*} p<0.05$.

TABLE 2 | Polynomial regression analyses results predicting followers' mindfulness.

\begin{tabular}{lc}
\hline $\begin{array}{l}\text { Dependent } \\
\text { variable }\end{array}$ & $\begin{array}{c}\text { Followers' } \\
\text { mindfulness }\end{array}$ \\
\hline Constant & $2.87(0.31)^{* *}$ \\
Age & $0.24(0.06)^{* *}$ \\
Gender & $-0.13(0.10)$ \\
Education & $-0.00(0.06)$ \\
Leader-follower dyadic tenure & $-0.06(0.05)$ \\
Follower's strategic optimism & $-0.08(0.10)$ \\
Leader's strategic optimism & $-0.08(0.09)$ \\
Follower's strategic optimism ${ }^{2}$ & $-0.05(0.12)$ \\
Follower's strategic optimism $\times$ leader's strategic optimism & $0.42(0.14)^{* *}$ \\
Leader's strategic optimism $^{2}$ & $-0.11(0.07)$ \\
$F$ & 3.29 \\
$d f$ & 281 \\
$R^{2}$ & 0.10
\end{tabular}

Congruence (follower's strategic optimism = leader's strategic optimism) line

Slope $\left(a_{1}\right)$

Curvature $\left(a_{2}\right)$

$-0.17(0.12)$

$0.25(0.10)^{*}$

Incongruence (follower's strategic

optimism = -leader's strategic optimism) line

Slope $\left(a_{3}\right)$

$0.00(0.09)$

Curvature $\left(a_{4}\right)$

$-0.59(0.22)^{* *}$

$N=291 .{ }^{*} p<0.05 ;{ }^{*} p<0.01$; the items reported are standardized beta coefficients; standard errors are in parentheses.

levels of what is a generally positive characteristic, per se, are not sufficient; it is necessary to provide a second view that provides a balance to that effect. When they are both in balance, in fact, at both low and high levels, our study revealed that they contribute to a follower's awareness of the leader-follower relationship (i.e., follower's mindfulness) and thereby to an increase in the follower's work engagement.

Third, we contribute to the mindfulness literature by examining followers' mindfulness as a crucial missing link in the relationship between leader-follower strategic optimism (mis)match and work engagement. Again, this notion relates back to ILT; followers' identification with a leader and employees' work setting is not determined solely by leader prototype
TABLE 3 | Results of the mediating analyses with the PROCESS macro.

\begin{tabular}{|c|c|c|}
\hline $\begin{array}{l}\text { Dependent } \\
\text { variable }\end{array}$ & $\begin{array}{l}\text { Followers } \\
\text { mindfulness }\end{array}$ & $\begin{array}{c}\text { Work } \\
\text { engagement }\end{array}$ \\
\hline Constant & $2.88^{* *}$ & $2.43^{* *}$ \\
\hline $\begin{array}{l}\text { Coefficient of the block variable } \\
\text { (i.e., FSO, LSO, } \mathrm{FSO}^{2}, \mathrm{FSO} \times \mathrm{LSO} \text {, } \\
\text { and } \mathrm{LSO}^{2} \text { ) }\end{array}$ & $1.22(0.38)^{*}$ & $0.72(0.38)^{*}$ \\
\hline Followers' mindfulness & - & $0.18(0.05)^{* *}$ \\
\hline Age & $0.24(0.06)^{* *}$ & $0.01(0.06)$ \\
\hline Gender & $-0.12(0.09)$ & $0.00(0.09)$ \\
\hline Education & $0.00(0.05)$ & $0.11(0.05)^{*}$ \\
\hline Leader-follower dyadic tenure & $-0.06(0.05)$ & $0.11(0.04)^{*}$ \\
\hline$F$ & 5.49 & 4.89 \\
\hline$d f$ & $(5,285)$ & $(6,284)$ \\
\hline$R^{2}$ & 0.08 & 0.09 \\
\hline $\begin{array}{l}\text { Indirect effect of leader-follower } \\
\text { strategic optimism (mis)match on } \\
\text { followers' work engagement via } \\
\text { followers' mindfulness }\end{array}$ & - & $\begin{array}{c}0.22 \text { (0.13)* (LLCl: } \\
0.05, \text { ULCl: } 0.57 \text { ) }\end{array}$ \\
\hline \multicolumn{3}{|c|}{$\begin{array}{l}N=291 .{ }^{*} p<0.05 ;{ }^{* *} p<0.01 \text {; unstandardized coefficients are reported (standard } \\
\text { errors in parentheses). FSO, Follower strategic optimism. LSO, Leader strategic } \\
\text { optimism. LLCl, lower level confidence interval. ULCI, upper level confidence } \\
\text { interval. The indirect effect was tested using bias-corrected percentile method with } \\
\text { bootstrapping 10,000 samples. } 95 \% \text { confidence intervals are represented. }\end{array}$} \\
\hline
\end{tabular}

(Lord et al., 1984; Shondrick et al., 2010), but also by the extent to which leaders and followers share common cognitive characteristics. Perceptions are thus crucial, and this is especially true when research is focused on the connection between mindfulness and leadership. Mindfulness represents an integral component in explaining how the match between followers' and leaders' cognitive characteristics leads to work engagement via followers' awareness (i.e., mindfulness) of that match, as well as of their work setting and the cognitive style of their leaders. Mindfulness thus embodies an important phenomenon that enables individuals at work to interpret their work settings and their dyadic interactions with leaders.

\section{Practical Implications}

The key practical implication of our study is related to ensuring leader-follower alignment in cognitive styles. Strategic optimism can be measured in advance, which should be a key informational 
element when establishing working follower-leader dyads or assigning followers to specific leaders. This seems to be a viable way of ensuring higher levels of employee mindfulness, and thereby promoting higher levels of work engagement, which has been shown to lead to motivation, innovation, and productivity (Schaufeli and Salanova, 2007).

The management of perceptions is also important, and represents an important aspect of the project of ensuring that the leader-follower match in cognitive styles is, in fact, interpreted as a congruence. Both participants in leader-follower dyads should be trained to prevent the development of perception biases (Černe et al., 2014; Hansbrough et al., 2015), while taking particular care to ensure that the cognitive style of a leader is made apparent to the follower through transparent and open communication. Training and development initiatives in organizations should thus focus on establishing highquality relationships at work through communication-improving exercises and fostering the socialization process at work (Dutton and Ragins, 2017).

Mindfulness is associated with increased self-reported perspective-taking, which includes understanding the behavior of others (Dekeyser et al., 2008). Similarly, mindfulness improves communication and heightens information accuracy, thereby decreasing conflicts in relationships (Wachs and Cordova, 2007). Because followers form a leadership picture based on their judgments of the characteristics that leaders ought to have (Funder and Sneed, 1993), accurately perceived information is crucial to the establishment of functionally effective leaderfollower relationships. Specifically, mindfulness training promotes the accuracy of followers' self-other perception, which helps individuals to adjust the "self-perceived picture" of a leader in accordance with the actual one, thus evoking desirable outcomes, such as higher levels of work engagement.

It should here be noted that a follower's optimism can be improved and cultivated, as shown by work on learned optimism (Seligman, 2011) and resource-based intervention programs (Costantini et al., 2017). Psychological capital (i.e., optimism) was able to increase positive work-related outcomes, such as work engagement. Therefore, organizational psychologists should focus on the developmental nature of optimism, as demonstrated by various positive psychology interventions and programs (Seligman et al., 2005; Costantini et al., 2017).

\section{Limitations and Future Research Suggestions}

As is true of any study, this research is not without its limitations. In this case, the limitations relate both to the study's empirical design and to its theoretical background, offering promising avenues for future research. First, our study was cross-sectional in nature and based on a single source (i.e., employees). Even though our research questions and constructs called for followers' assessments of phenomena they experience at work and thereby could not be other-rated, future studies could, perhaps, aim to tap into work engagement from the leader's perspective or could examine other individual performance measures that might be more objectively rated by other sources.
Research has shown that attention can be improved by noticing novel things (Langer, 2000; Langer and Moldoveanu, 2000) or/and by low-dose mindfulness interventions, such as mindfully washing dishes (Hanley et al., 2015). However, a second and related limitation involves the causality in our proposed and tested relationships, which, although based on theory, cannot be ascertained in a sufficiently definite manner; to that end, future research should adopt longitudinal research designs (e.g., through a diary study).

Third, by focusing on leaders' and followers' strategic optimism, we have only scratched the surface of cognitive processing and leadership research. Additional promising constructs that could be examined, with respect to leaderfollower (mis)match examination and mindfulness, include thinking styles (Cheek and Norem, 2017) and elements of positive psychological capital that depend less on cognitive processing and more on affective processing, e.g., hope, resiliency, confidence, and general optimism (Luthans et al., 2010). Future studies could also focus on conditions and outcomes in which the leaderfollower mismatch, in terms of a certain characteristic, could potentially be beneficial; this would represent an even further extension of the trend in organizational psychology research of examining the boundary conditions of positive phenomena that have negative effects (Pierce and Aguinis, 2013), and vice versa.

Finally, although this model makes sense from an intuitive standpoint and provides valuable results in terms of explaining the quality of the leader-follower relationship, it is still built only on quantitatively measured followers' perceptions. As such, qualitative data collected in future research could potentially be used to clarify some of its complex nuances. Therefore, it behooves us to continue deepening our understanding of the leader-follower (mis)match in organizations and of the outcomes and implications of this (mis)match.

\section{ETHICS STATEMENT}

This study was carried out in accordance with the recommendations of Core Practices and Guidelines published by the Committee on Publication Ethics. The protocol was approved by the Committee of Research Ethics at the Faculty of Economics, University of Ljubljana. All subjects (field study respondents) gave written informed consent.

\section{AUTHOR CONTRIBUTIONS}

Both authors contributed to conceptualizing the study and its research design, collecting the data, analyzing it, and writing it up.

\section{FUNDING}

European Commission Slovene Research Agency (Project Code: J5-9329). Faculty of Economics University of Ljubljana (Internal Grant "Humanizing Innovation in Digital Work"). Slovene Research Agency (Research core Funding No. P5-0410). 


\section{REFERENCES}

Aiken, L. S., West, S. G., and Reno, R. R. (1991). Multiple Regression: Testing and Interpreting Interactions. Newbury Park, CA: Sage.

Albrecht, S. L., and Andreetta, M. (2011). The influence of empowering leadership, empowerment and engagement on affective commitment and turnover intentions in community health service workers: test of a model. Leadersh. Health Serv. 24, 228-237. doi: 10.1108/1751187111115 1126

Avery, D. R., McKay, P. F., and Wilson, D. C. (2007). Engaging the aging workforce: the relationship between perceived age similarity, satisfaction with coworkers, and employee engagement. J. Appl. Psychol. 92, 1542-1556. doi: 10.1037/00219010.92.6.1542

Avey, J. B., Avolio, B. J., and Luthans, F. (2011). Experimentally analyzing the impact of leader positivity on follower positivity and performance. Leadersh. Q. 22, 282-294. doi: 10.1016/j.leaqua.2011.02.004

Avey, J. B., Luthans, F., and Jensen, S. M. (2009). Psychological capital: a positive resource for combating employee stress and turnover. Hum. Resour. Manag. 48, 677-693. doi: 10.1002/hrm.20294

Baer, R. A., Smith, G. T., Hopkins, J., Krietemeyer, J., and Toney, L. (2006). Using self-report assessment methods to explore facets of mindfulness. Assessment 13, 27-45. doi: 10.1177/1073191105283504

Becker, T. E., Atinc, G., Breaugh, J. A., Carlson, K. D., Edwards, J. R., and Spector, P. E. (2016). Statistical control in correlational studies: 10 essential recommendations for organizational researchers. J. Organ. Behav. 37, 157-167. doi: $10.1002 /$ job. 2053

Biddle, B. J. (1979). Role Theory: Expectations, Identities, and Behaviors. New York, NY: Academic Press.

Bishop, S. R., Lau, M., Shapiro, S., Carlson, L., Anderson, N. D., Carmody, J., et al. (2004). Mindfulness: a proposed operational definition. Clin. Psychol. 11, 230-241. doi: 10.1093/clipsy.bph077

Blaskovics, B. (2014). Impact of leadership styles on project success - the case of a multinational company. Dyn. Relationsh. Manag. J. 3, 21-36. doi: 10.17708/ DRMJ.2014.v03n02a02

Bligh, M. C. (2011). "Followership and follower-centered approaches," in The Sage Handbook of Leadership, eds A. Bryman, D. Collinson, K. Grint, B. Jackson, and M. Uhl-Bien (London: SAGE Publications), 393-403.

Brouer, R. L., Duke, A., Treadway, D. C., and Ferris, G. R. (2009). The moderating effect of political skill on the demographic dissimilarity: leader-member exchange quality relationship. Leadersh. Q. 20, 61-69. doi: 10.1016/j.leaqua. 2009.01.015

Brown, K. W., and Ryan, R. M. (2003). The benefits of being present: mindfulness and its role in psychological well-being. J. Pers. Soc. Psychol. 84, 822-848. doi: 10.1037/0022-3514.84.4.822

Bunjak, A., and Černe, M. (2018). The role of leader-follower defensive pessimism (in)congruence in fostering perceptions of followers' isolation. Econ. Bus. Rev. 20, 129-157.

Buunk, B. P., Doosje, B. J., Jans, L. G., and Hopstaken, L. E. (1993). Perceived reciprocity, social support, and stress at work: the role of exchange and communal orientation. J. Pers. Soc. Psychol. 65, 801-811. doi: 10.1037/00223514.65.4.801

Cable, D. M., and Edwards, J. R. (2004). Complementary and supplementary fit: a theoretical and empirical integration. J. Appl. Psychol. 89, 822-834. doi: 10. 1037/0021-9010.89.5.822

Cameron, K., and McNaughtan, J. (2014). Positive organizational change. J. Appl. Behav. Sci. 50, 445-462. doi: 10.1177/0021886314549922

Carlson, E. N. (2013). Overcoming the barriers to self-knowledge: mindfulness as a path to seeing yourself as you really are. Perspect. Psychol. Sci. 8, 173-186. doi: $10.1177 / 1745691612462584$

Cavazotte, F., Moreno, V., and Hickmann, M. (2012). Effects of leader intelligence, personality and emotional intelligence on transformational leadership and managerial performance. Leadersh. Q. 23, 443-455. doi: 10.1016/j.leaqua.2011. 10.003

Černe, M., Dimovski, V., Marič, M., Penger, S., and Škerlavaj, M. (2014). Congruence of leader self-perceptions and follower perceptions of authentic leadership: understanding what authentic leadership is and how it enhances employees' job satisfaction. Aust. J. Manag. 39, 453-471. doi: 10.1177/ 0312896213503665
Chalofsky, N., and Krishna, V. (2009). Meaningfulness, commitment, and engagement: the intersection of a deeper level of intrinsic motivation. Adv. Dev. Hum. Resour. 11, 189-203. doi: 10.1177/1523422309333147

Chang, E. C., Chang, R., and Sanna, L. J. (2009). Optimism, pessimism, and motivation: relations to adjustment. Soc. Pers. Psychol. Compass 3, 494-506. doi: $10.1111 / j .1751-9004.2009 .00190 . x$

Cheek, N. N., and Norem, J. K. (2017). Holistic thinkers anchor less: exploring the roles of self-construal and thinking styles in anchoring susceptibility. Pers. Individ. Differ. 115, 174-176. doi: 10.1016/j.paid.2016.01.034

Chiesa, A. (2013). The difficulty of defining mindfulness: current thought and critical issues. Mindfulness 4, 255-268. doi: 10.1007/s12671-012-0123-4

Cornelis, I., Van Hiel, A., and De Cremer, D. (2006). Effects of procedural fairness and leader support on interpersonal relationships among group members. Group Dyn. Theory Res. Pract. 10, 309-328. doi: 10.1037/1089-2699. 10.4.309

Costantini, A., De Paola, F., Ceschi, A., Sartori, R., Meneghini, A. M., and Di Fabio, A. (2017). Work engagement and psychological capital in the Italian public administration: a new resource-based intervention programme. $S A J$ Ind. Psychol. 43, 1-11. doi: 10.4102/sajip.v43i0.1413

Dekeyser, M., Raes, F., Leijssen, M., Leysen, S., and Dewulf, D. (2008). Mindfulness skills and interpersonal behaviour. Pers. Individ. Differ. 44, 1235-1245. doi: 10.1016/j.paid.2007.11.018

Dinh, J. E., and Lord, R. G. (2012). Implications of dispositional and process views of traits for individual difference research in leadership. Leadersh. Q. 23, 651-669. doi: 10.1016/j.leaqua.2012.03.003

Dutton, J. E., and Ragins, B. R. (eds). (2017). "Positive relationships at work: an introduction and invitation," in Exploring Positive Relationships at Work, (New York, NY: Psychology Press), 2-24. doi: 10.4324/9781315094199

Dvir, T., and Shamir, B. (2003). Follower developmental characteristics as predicting transformational leadership: a longitudinal field study. Leadersh. Q. 14, 327-344. doi: 10.1016/S1048-9843(03)00018-3

Eagly, A. H., and Karau, S. J. (2002). Role congruity theory of prejudice toward female leaders. Psychol. Rev. 109, 573-598. doi: 10.1037/0033-295X.109.3.573

Eberth, J., and Sedlmeier, P. (2012). The effects of mindfulness meditation: a meta-analysis. Mindfulness 3, 174-189. doi: 10.1007/s12671-012-0101-x

Edwards, D. J., McEnteggart, C., Barnes-Holmes, Y., Lowe, R., Evans, N., and Vilardaga, R. (2017). The impact of mindfulness and perspective-taking on implicit associations toward the elderly: a relational frame theory account. Mindfulness 8, 1615-1622. doi: 10.1007/s12671-017-0734-x

Edwards, J. R. (2002). "Alternatives to difference scores: polynomial regression and response surface methodology," in The Jossey-Bass Business \& Management Series. Measuring and Analyzing Behavior in Organizations: Advances in Measurement and Data Analysis, eds F. Drasgow and N. Schmitt (San Francisco, CA: Jossey-Bass), 350-400.

Edwards, J. R., and Cable, D. M. (2009). The value of value congruence. J. Appl. Psychol. 94, 654-677. doi: 10.1037/a0014891

Edwards, J. R., and Parry, M. E. (1993). On the use of polynomial regression equations as an alternative to difference scores in organizational research. Acad. Manag. J. 36, 1577-1613.

Engle, E. M., and Lord, R. G. (1997). Implicit theories, self-schemas, and leadermember exchange. Acad. Manag. J. 40, 988-1010.

Epitropaki, O., and Martin, R. (2004). Implicit leadership theories in applied settings: factor structure, generalizability, and stability over time. J. Appl. Psychol. 89, 293-310. doi: 10.1037/0021-9010.89.2.293

Epitropaki, O., Sy, T., Martin, R., Tram-Quon, S., and Topakas, A. (2013). Implicit leadership and followership theories "in the wild": taking stock of informationprocessing approaches to leadership and followership in organizational settings. Leadersh. Q. 24, 858-881. doi: 10.1016/j.leaqua.2013.10.005

Feldman, G., Greeson, J., and Senville, J. (2010). Differential effects of mindful breathing, progressive muscle relaxation, and loving-kindness meditation on decentering and negative reactions to repetitive thoughts. Behav. Res. Ther. 48, 1002-1011. doi: 10.1016/j.brat.2010.06.006

Felfe, J., and Schyns, B. (2010). Followers' personality and the perception of transformational leadership: further evidence for the similarity hypothesis. $\mathrm{Br}$. J. Manag. 21, 393-410.

Fischer, I. (2009). Friend or foe: subjective expected relative similarity as a determinant of cooperation. J. Exp. Psychol. 138, 341-350. doi: 10.1037/ a0016073 
Fleenor, J. W., Smither, J. W., Atwater, L. E., Braddy, P. W., and Sturm, R. E. (2010). Self-other rating agreement in leadership: a review. Leadersh. Q. 21, 1005-1034. doi: 10.1016/j.leaqua.2010.10.006

Funder, D. C., and Sneed, C. D. (1993). Behavioral manifestations of personality: an ecological approach to judgmental accuracy. J. Pers. Soc. Psychol. 64, 479-490. doi: 10.1037/0022-3514.64.3.479

Galinsky, A. D., and Moskowitz, G. B. (2000). Perspective-taking: decreasing stereotype expression, stereotype accessibility, and in-group favoritism. J. Pers. Soc. Psychol. 78, 708-724. doi: 10.1037/0022-3514.78.4.708

Gardner, W. L., Avolio, B. J., Luthans, F., May, D. R., and Walumbwa, F. (2005). "Can you see the real me?" A self-based model of authentic leader and follower development. Leadersh. Q. 16, 343-372. doi: 10.1016/j.leaqua.2005.03.003

Good, D. J., Lyddy, C. J., Glomb, T. M., Bono, J. E., Brown, K. W., Duffy, M. K., et al. (2016). Contemplating mindfulness at work: an integrative review. J. Manag. 42, 114-142. doi: 10.1177/0149206315617003

Gooty, J., Gavin, M., Johnson, P. D., Frazier, M. L., and Snow, D. B. (2009). In the eyes of the beholder: transformational leadership, positive psychological capital, and performance. J. Leadersh. Organ. Stud. 15, 353-367. doi: 10.1177/ 1548051809332021

Gosling, S. D., Rentfrow, P. J., and Swann, W. B. Jr. (2003). A very brief measure of the Big-Five personality domains. J. Res. Pers. 37, 504-528. doi: 10.1177/ 1359105317720819

Grabovac, A. D., Lau, M. A., and Willett, B. R. (2011). Mechanisms of mindfulness: a Buddhist psychological model. Mindfulness 2, 154-166. doi: 10.1007/s12671011-0054-5

Graen, G. B., and Uhl-Bien, M. (1995). Relationship-based approach to leadership: development of leader-member exchange (LMX) theory of leadership over 25 years: applying a multi-level multi-domain perspective. Leadersh. Q. 6, 219-247. doi: 10.1016/1048-9843(95)90036-5

Hall, R. J., and Lord, R. G. (1995). Multi-level information-processing explanations of followers' leadership perceptions. Leadersh. Q. 6, 265-287. doi: 10.1016/10489843(95)90010-1

Hanley, A. W., Warner, A. R., Dehili, V. M., Canto, A. I., and Garland, E. L. (2015). Washing dishes to wash the dishes: brief instruction in an informal mindfulness practice. Mindfulness 6, 1095-1103. doi: 10.1007/s12671-014-0360-9

Hansbrough, T. K., Lord, R. G., and Schyns, B. (2015). Reconsidering the accuracy of follower leadership ratings. Leadersh. Q. 26, 220-237. doi: 10.1016/j.leaqua. 2014.11.006

Harrison, D. A., Price, K. H., Gavin, J. H., and Florey, A. T. (2002). Time, teams, and task performance: changing effects of surface- and deep-level diversity on group functioning. Acad. Manag. J. 45, 1029-1045. doi: 10.5465/3069328

Hayes, A. F. (2013). Introduction to Mediation, Moderation, and Conditional Process Analysis: A Regression-Based Approach. New York, NY: Guilford Press.

Howell, J. M., and Shamir, B. (2005). The role of followers in the charismatic leadership process: relationships and their consequences. Acad. Manag. Rev. 30, 96-112. doi: 10.5465/amr.2005.15281435

Ilies, R., Morgeson, F. P., and Nahrgang, J. D. (2005). Authentic leadership and eudaemonic well-being: understanding leader-follower outcomes. Leadersh. Q. 16, 373-394. doi: 10.1016/j.leaqua.2005.03.002

Jha, A. P., Krompinger, J., and Baime, M. J. (2007). Mindfulness training modifies subsystems of attention. Cogn. Affect. Behav. Neurosci. 7, 109-119. doi: 10.3758/ CABN.7.2.109

Jones, J. R., and Harter, J. K. (2005). Race effects on the employee engagementturnover intention relationship. J. Leadersh. Organ. Stud. 11, 78-88. doi: 10. 1111/jocn.14311

Junker, N. M., and van Dick, R. (2014). Implicit theories in organizational settings: a systematic review and research agenda of implicit leadership and followership theories. Leadersh. Q. 25, 1154-1173. doi: 10.1016/j.leaqua.2014.09.002

Kabat-Zinn, J. (2003). Mindfulness-based interventions in context: past, present, and future. Clin. Psychol. 10, 144-156. doi: 10.1093/clipsy.bpg016

Keller, T. (1999). Images of the familiar: individual differences and implicit leadership theories. Leadersh. Q. 10, 589-607. doi: 10.1016/S1048-9843(99) 00033-8

Keller, T. (2003). Parental images as a guide to leadership sensemaking: an attachment perspective on implicit leadership theories. Leadersh. Q. 14, 141-160. doi: 10.1016/S1048-9843(03)00007-9

Kristof-Brown, A. L., Zimmerman, R. D., and Johnson, E. C. (2005). Consequences of individuals' fit at work: a meta-analysis of person-job, person-organization, person-group, and person-supervisor fit. Pers. Psychol. 58, 281-342. doi: 10. $1111 / j .1744-6570.2005 .00672 . x$
Langer, E. J. (2000). Mindful learning. Curr. Dir. Psychol. Sci. 9, 220-223. doi: 10.1111/1467-8721.00099

Langer, E. J., and Moldoveanu, M. (2000). The construct of mindfulness. J. Soc. Issues 56, 1-9. doi: 10.1111/0022-4537.00148

Leroy, H., Anseel, F., Dimitrova, N. G., and Sels, L. (2013). Mindfulness, authentic functioning, and work engagement: a growth modeling approach. J. Vocat. Behav. 82, 238-247. doi: 10.1016/j.jvb.2013.01.012

Leroy, H., Anseel, F., Gardner, W. L., and Sels, L. (2015). Authentic leadership, authentic followership, basic need satisfaction, and work role performance: a cross-level study. J. Manag. 41, 1677-1697. doi: 10.1177/0149206312457822

Lindell, M. K., and Whitney, D. J. (2001). Accounting for common method variance in cross-sectional research designs. J. Appl. Psychol. 86, 114-121. doi: 10.1037/0021-9010.86.1.114

Lord, R. G., and Brown, D. J. (2001). Leadership, values, and subordinate selfconcepts. Leadersh. Q. 12, 133-152. doi: 10.1007/s10943-011-9479-3

Lord, R. G., and Brown, D. J. (2004). Leadership Processes and Follower Self-Identity. Mahwah, NJ: Erlbaum.

Lord, R. G., Brown, D. J., Harvey, J. L., and Hall, R. J. (2001). Contextual constraints on prototype generation and their multilevel consequences for leadership perceptions. Leadersh. Q. 12, 311-338. doi: 10.1016/S1048-9843(01)00081-9

Lord, R. G., Foti, R. J., and De Vader, C. L. (1984). A test of leadership categorization theory: internal structure, information processing, and leadership perceptions. Organ. Behav. Hum. Perform. 34, 343-378. doi: 10.1016/0030-5073(84)90043-6

Lord, R. G., and Hall, R. (2003). "Identity, leadership categorization, and leadership schema," in Leadership and Power: Identity Processes in Groups and Organizations, eds D. van Knippenberg and M. Hogg (London: Sage), 48-64.

Lord, R. G., and Maher, K. J. (1991). "Cognitive theory in industrial and organizational psychology," in Handbook of Industrial and Organizational Psychology, Vol. 2, eds M. D. Dunnette and L. M. Hough (Palo Alto, CA: Consulting Psychologists Press), 1-62.

Luthans, F., Avey, J. B., Avolio, B. J., and Peterson, S. J. (2010). The development and resulting performance impact of positive psychological capital. Hum. Resour. Dev. Q. 21, 41-67. doi: 10.1002/hrdq.20034

Luthans, F., and Avolio, B. J. (2009). The "point" of positive organizational behavior. J. Organ. Behav. 30, 291-307. doi: 10.1002/job.589

Luthans, F., Avolio, B. J., Avey, J. B., and Norman, S. M. (2007). Positive psychological capital: measurement and relationship with performance and satisfaction. Pers. Psychol. 60, 541-572. doi: 10.1136/bmjqs-2017-006847

Malinowski, P., and Lim, H. J. (2015). Mindfulness at work: positive affect, hope, and optimism mediate the relationship between dispositional mindfulness, work engagement, and well-being. Mindfulness 6, 1250-1262. doi: 10.1007/ s12671-015-0388-5

Mauno, S., Kinnunen, U., Mäkikangas, A., and Nätti, J. (2005). Psychological consequences of fixed-term employment and perceived job insecurity among health care staff. Eur. J. Work Organ. Psychol. 14, 209-237. doi: 10.1080/ 13594320500146649

Medvedeff, M. E., Lord, R. G., Shamir, B., Pallai, R., Bligh, M. C., and UhlBien, M. (2007). "Implicit leadership theories as dynamic processing structures," in Followercentered Perspectives on Leadership: A Tribute to the Memory of James R. Meindl, eds B. Shamir, R. Pillai, M. C. Bligh, and M. Uhl-Bien (Greenwich, CT: Information Age), 19-50.

Meuser, J. D., Gardner, W. L., Dinh, J. E., Hu, J., Liden, R. C., and Lord, R. G. (2016). A network analysis of leadership theory: the infancy of integration. J. Manag. 42, 1374-1403. doi: 10.1177/0149206316647099

Mikulas, W. L. (2011). Mindfulness: significant common confusions. Mindfulness 2, 1-7. doi: 10.1007/s12671-010-0036-z

Montoya, R. M., and Horton, R. S. (2013). A meta-analytic investigation of the processes underlying the similarity-attraction effect. J. Soc. Pers. Relat. 30, 64-94. doi: 10.1177/0265407512452989

Montoya, R. M., Horton, R. S., and Kirchner, J. (2008). Is actual similarity necessary for attraction? A meta-analysis of actual and perceived similarity. J. Soc. Pers. Relat. 25, 889-922. doi: 10.1177/0265407508096700

Mrazek, M. D., Franklin, M. S., Phillips, D. T., Baird, B., and Schooler, J. W. (2013). Mindfulness training improves working memory capacity and GRE performance while reducing mind wandering. Psychol. Sci. 24, 776-781. doi: $10.1177 / 0956797612459659$

Norem, J. K. (2001). "Defensive pessimism, optimism, and pessimism," in Optimism and Pessimism: Implications for Theory, Research, and Practice, ed. E. C. Chang (Washington, DC: American Psychological Association), 77-100. doi: $10.1037 / 10385-004$ 
Norem, J. K., and Illingworth, K. S. (1993). Strategy-dependent effects of reflecting on self and tasks: some implications of optimism and defensive pessimism. J. Pers. Soc. Psychol. 65, 822-835. doi: 10.1037/0022-3514.65.4.822

Oakes, P. J., Turner, J. C., and Haslam, S. A. (1991). Perceiving people as group members: the role of fit in the salience of social categorizations. Br. J. Soc. Psychol. 30, 125-144. doi: 10.1111/j.2044-8309.1991.tb00930.x

Parker, S. K., and Axtell, C. M. (2001). Seeing another viewpoint: antecedents and outcomes of employee perspective taking. Acad. Manag. J. 44, 1085-1100.

Pelham, B. W., Carvallo, A., and Jones, J. T. (2005). Implicit egotism. Curr. Dir. Psychol. Sci. 14, 106-110. doi: 10.1111/j.0963-7214.2005.00344.x

Pelham, B. W., Mirenberg, M. C., and Jones, J. T. (2002). Why Susie sells seashells by the seashore: implicit egotism and major life decisions. J. Pers. Soc. Psychol. 82, 469-487. doi: 10.1037/0022-3514.82.4.469

Pierce, J. R., and Aguinis, H. (2013). The too-much-of-a-good-thing effect in management. J. Manag. 39, 313-338. doi: 10.1037/pspp0000147

Pircher Verdorfer, A. (2016). Examining mindfulness and its relations to humility, motivation to lead, and actual servant leadership behaviors. Mindfulness 7, 950-961. doi: 10.1007/s12671-016-0534-8

Pirola-Merlo, A., Härtel, C., Mann, L., and Hirst, G. (2002). How leaders influence the impact of affective events on team climate and performance in R\&D teams. Leadersh. Q. 13, 561-581. doi: 10.1016/S1048-9843(02)00144-3

Preacher, K. J., and Hayes, A. F. (2004). SPSS and SAS procedures for estimating indirect effects in simple mediation models. Behav. Res. Methods Instr. Comput. 36, 717-731. doi: 10.3758/BF03206553

Reis, H. T., Collins, W. A., and Berscheid, E. (2000). The relationship context of human behavior and development. Psychol. Bull. 126, 844-872. doi: 10.1037/ 0033-2909.126.6.844

Rich, B. L., Lepine, J. A., and Crawford, E. R. (2010). Job engagement: antecedents and effects on job performance. Acad. Manag. J. 53, 617-635. doi: 10.5465/amj. 2010.51468988

Ritter, B. A., and Lord, R. G. (2007). The impact of previous leaders on the evaluation of new leaders: an alternative to prototype matching. J. Appl. Psychol. 92, 1683-1695. doi: 10.1037/0021-9010.92.6.1683

Rowold, J., and Schlotz, W. (2009). Transformational and transactional leadership and followers' chronic stress. Leadersh. Rev. 9, 35-48.

Schaufeli, W., and Salanova, M. (2007). "Work engagement: an emerging psychological concept and its implications for organizations," in Research in Social Issues in Management: Managing Social and Ethical Issues in Organizations, Vol. 5, eds S. W. Gilliland, D. D. Steiner, and D. P. Skarlicki (Greenwich, CT: Information Age Publishers), 135-177.

Schaufeli, W. B., Salanova, M., González-Romá, V., and Bakker, A. B. (2002). The measurement of engagement and burnout: a two sample confirmatory factor analytic approach. J. Happiness Stud. 3, 71-92. doi: 10.1023/A:1015630930326

Scheier, M. E., and Carver, C. S. (1987). Dispositional optimism and physical wellbeing: the influence of generalized outcome expectancies on health. J. Pers. 55, 169-210. doi: 10.1111/j.1467-6494.1987.tb00434.x

Schyns, B., and Day, D. (2010). Critique and review of leader-member exchange theory: issues of agreement, consensus, and excellence. Eur. J. Work Organ. Psychol. 19, 1-29. doi: 10.1080/13594320903024922

Schyns, B., and Meindl, J. R. (eds). (2005). "An overview of implicit leadership theories and their application in organization practice," in Implicit Leadership Theories: Essays and Explorations, (Greenwich, CT: Information Age Publishing), 15-36.

Schyns, B., and Sanders, K. (2007). In the eyes of the beholder: personality and the perception of leadership 1. J. Appl. Soc. Psychol. 37, 2345-2363. doi: 10.1037/ pag0000186

Scott, K. A., and Brown, D. J. (2006). Female first, leader second? Gender bias in the encoding of leadership behavior. Organ. Behav. Hum. Decis. Process. 101, 230-242. doi: 10.1016/j.obhdp.2006.06.002

Seligman, M. E., Steen, T. A., Park, N., and Peterson, C. (2005). Positive psychology progress: empirical validation of interventions. Am. Psychol. 60, 410-421. doi: 10.1037/0003-066X.60.5.410

Seligman, M. E. P. (2011). Learned Optimism: How to Change Your Mind and Your Life. New York, NY: Vintage.

Shamir, B. (2007). "From passive recipients to active co-producers: the roles of followers in the leadership process," in Follower-Centered Perspectives on Leadership: A Tribute to J. R. Meindl, eds B. Shamir, R. Pillai, M. Bligh, and M. Uhl-Bien (Stamford, CT: Information Age Publishing).
Shondrick, S. J., Dinh, J. E., and Lord, R. G. (2010). Developments in implicit leadership theory and cognitive science: applications to improving measurement and understanding alternatives to hierarchical leadership. Leadersh. Q. 21, 959-978. doi: 10.1016/j.leaqua.2010. 10.004

Sluss, D. M., and Ashforth, B. E. (2007). Relational identity and identification: defining ourselves through work relationships. Acad. Manag. Rev. 32, 9-32. doi: 10.5465/amr.2007.23463672

Spencer, S. M., and Norem, J. K. (1996). Reflection and distraction defensive pessimism, strategic optimism, and performance. Pers. Soc. Psychol. Bull. 22, 354-365. doi: $10.1177 / 0146167296224003$

Sy, T. (2010). What do you think of followers? Examining the content, structure, and consequences of implicit followership theories. Organ. Behav. Hum. Decis. Process. 113, 73-84. doi: 10.1016/j.obhdp.2010.06.001

Taylor, S. E., and Brown, J. D. (1988). Illusion and well-being: a social psychological perspective on mental health. Psychol. Bull. 103, 193-210. doi: 10.1037/00332909.103.2.193

Teasdale, J. D., Moore, R. G., Hayhurst, H., Pope, M., Williams, S., and Segal, Z. V. (2002). Metacognitive awareness and prevention of relapse in depression: empirical evidence. J. Consult. Clin. Psychol. 70, 275-287. doi: 10.1037/0022006X.70.2.275

Tims, M., Bakker, A. B., and Xanthopoulou, D. (2011). Do transformational leaders enhance their followers' daily work engagement? Leadersh. Q. 22, 121-131. doi: 10.1016/j.leaqua.2010.12.011

Toma, C., Corneille, O., and Yzerbyt, V. (2012). Holding a mirror up to the self: egocentric similarity beliefs underlie social projection in cooperation. Pers. Soc. Psychol. Bull. 38, 1259-1271. doi: 10.1177/0146167212449022

Uhl-Bien, M., Riggio, R. E., Lowe, K. B., and Carsten, M. K. (2014). Followership theory: a review and research agenda. Leadersh. Q. 25, 83-104. doi: 10.1016/j. leaqua.2013.11.007

Van Breukelen, W., Konst, D., and Van Der Vlist, R. (2002). Effects of LMX and differential treatment on work unit commitment. Psychol. Rep. 91, 220-230. doi: 10.2466/PR0.91.5.220-230

van Gils, S., van Quaquebeke, N., and van Knippenberg, D. (2010). The X-factor: on the relevance of implicit leadership and followership theories for leadermember exchange agreement. Eur. J. Work Organ. Psychol. 19, 333-363. doi: 10.1080/13594320902978458

van Quaquebeke, N., van Knippenberg, D., and Eckloff, T. (2011). Individual differences in the leader categorization to openness to influence relationship: the role of followers' self-perception and social comparison orientation. Group Process. Intergroup Relat. 14, 605-622. doi: 10.1177/136843021039 1311

Von Hippel, W., and Trivers, R. (2011). Reflections on self-deception. Behav. Brain Sci. 34, 41-56. doi: 10.1348/147608309X450508

Wachs, K., and Cordova, J. V. (2007). Mindful relating: exploring mindfulness and emotion repertoires in intimate relationships. J. Marital Fam. Ther. 33, 464-481. doi: 10.1111/j.1752-0606.2007.00032.x

Watson, D., Hubbard, B., and Wiese, D. (2000). Self-other agreement in personality and affectivity: the role of acquaintanceship, trait visibility, and assumed similarity. J. Pers. Soc. Psychol. 78, 546-558. doi: 10.1037/0022-3514. 78.3.546

Youssef, C. M., and Luthans, F. (2007). Positive organizational behavior in the workplace: the impact of hope, optimism, and resilience. J. Manag. 33, 774-800. doi: $10.1177 / 0149206307305562$

Zeidan, F., Johnson, S. K., Diamond, B. J., David, Z., and Goolkasian, P. (2010). Mindfulness meditation improves cognition: evidence of brief mental training. Conscious. Cogn. 19, 597-605. doi: 10.1016/j.concog.2010.03.014

Conflict of Interest Statement: The authors declare that the research was conducted in the absence of any commercial or financial relationships that could be construed as a potential conflict of interest.

Copyright (c) 2018 Bunjak and Črne. This is an open-access article distributed under the terms of the Creative Commons Attribution License (CC BY). The use, distribution or reproduction in other forums is permitted, provided the original author(s) and the copyright owner(s) are credited and that the original publication in this journal is cited, in accordance with accepted academic practice. No use, distribution or reproduction is permitted which does not comply with these terms. 